\title{
Model Peran Pemerintah pada Pengembangan Inovasi UKM dengan Pendekatan Structural Equation Modeling (SEM)
}

\author{
Abdul Rasyid ${ }^{1)}$, Fentje Abdul Rauf ${ }^{2)}$ \\ 1),2) Jurusan Teknik Industri, Fakultas Teknik, Universitas Negeri Gorontalo \\ email: abdul.rasyid@ung.ac.id
}

\begin{abstract}
Abstrak
Usaha Kecil dan Menengah (UKM) telah memberikan peran yang sangat penting bagi perekonomian nasional dan memberikan kontribusi yang besar dan terus meningkat setiap tahunnya pada penyerapan tenaga kerja dan pendapatan negara.. Dalam perkembangan UKM menghadapi kendalaseperti inovasi yang menyebabkan kurangnya kopentensi dalam menghadapi era industri 4.0. Peran Pemerintah dapat memberikan kontribusi pada peningkatan inovasi pada UKM. Pemerintah merupakan institusi dalam mengeluarkan dan menjalankan kebijakan dapat menggerakkan lahirnya inovasi pada UKM. Pada penelitian melihat peran Pemerintah dan mengidentifikasi faktor-faktor yang mempengaruhi inovasi pada UKM dengan menggunakan pendekatan Structural Equation Modeling (SEM). Berdasarkan pengolahan data dengan menggunan SEM didapatkan bahwa Pemerintah dapat mempengaruhi pengembangan inovasi UKM melalui: pembelajaran dan peningkatan penggunaan teknologi informasi.
\end{abstract}

Kata Kunci: UKM, inovasi, Pemerintah.

\begin{abstract}
Small and Medium Enterprises (SMEs) have a very important role in the national economy and is making a large and increasing contribution every year to the absorption of labour and state income. The development of SMEs face challenges such as lack of innovations that cause a lack of competence when facing the 4.0 industrial era. The Government can contribute to increasing innovation among SMEs. The government is an institution which can issue and implement policies that can drive the birth of innovation in SMEs. The research looks at the role of the Government and identifies the factors that influence innovation in SMEs by using Structural Equation Modelling (SEM) approach. Based on data processing using SEM it is found that the Government can influence the development of SME innovation through learning and increasing the use of information technology.
\end{abstract}

Keywords: SME, innovation, government

\section{Pendahuluan}

Peranan Usaha Mikro Kecil dan Menengah (UMKM) sangat penting dalam pembangunan ekonomi nasional. Selain berperan pada pertumbuhan ekonomi dan penyerapan tenaga kerja, UKM juga berperan dalam meningkatkan pendapatan domestik bruto. Hal ini dapat dilihat pada tabel berikut:

Tabel 1. Peran UKM pada penyerapan tenaga kerja dan PDB

\begin{tabular}{lcrrr}
\hline \multicolumn{1}{c}{ INDIKATOR } & SATUAN & TAHUN 2015 & TAHUN 2016 & TAHUN 2017 \\
\hline Unit Usaha & (Unit) & 59.262 .772 & 61.651 .177 & 62.922 .617 \\
Tenaga Kerja & (Orang) & 123.229 .386 & 112.828 .610 & 116.673 .416 \\
PDB & (Rp. M) & 6.228 .285 & $7.009 .283,00$ & $7.704 .635,90$ \\
\hline
\end{tabular}

Sumber : Kemenkop UKM (2018), data yang diolah 
UKM juga memberikan peran yang besar terhadap pertahanan ekonomi indonesia dalam menghadapi krisis global dan juga merupakan sektor yang dapat menekan tingkat ketimpangan baik ekonomi dan sosial. Dapat disimpulkan bahwa UKM adalah lokomotif dalam roda perekonomian yang mempunyai peran yang strategis dalam membangun perekonomian suatu negara ataupun daerah (Chughtai 2014; Ogbuanu, Kabuoh, and Okwu 2018).

UKM Indonesia saat ini mengalami peningkatan meskipun masih terdapat beberapa kendala. Dalam perkembangannya, UKM Indonesia mengalami berbagai kendala dalam menyambut persaingan bebas dan era industri 4.0. Permasalahan utama yang menghambat perkembangan UKM diantaranya keterbatasan modal, teknologi, kesulitan dalam pemasaran, keterbatasan dalam mengakses informasi tentang peluang pasar, sumber daya manusia (tenaga kerja) yang memiliki soft skill rendah (Chughtai 2014).

UKM yang berada di negara-negara berkembang khususnya Indonesia masih mengalami hambatan terkait dengan willingness to innovate dan kurang memiliki kemampuan untuk mengakses sumber daya eksternal, jika dibandingkan dengan perusahaan-perusahaan yang berskala besar (Belo et al., 2015). UKM di Indonesia masih sangat perlu untuk didorong dan diberikan pemahaman agar mau mengembangkan kemampuannya untuk melakukan inovasi dalam usahanya untuk menghasilkan produk-produk yang mampu berdaya saing (Tambunan, 2009, Herliana, 2015, Nugroho et al., 2017).

Peningkatan inovasi pada UKM bisa dilakukan melalui peran Pemerintah dan peran pemerintah (Herliana, 2015, Nugroho et al., 2017). Peningkatan Linkage Pendidikan Tinggi terhadap UKM dapat diwujudkan dalam bentuk kerjasama dengan UKM, mengembangkan program yang komprehensif dan pengembangan brand equity pada UKM (Tamba, 2017).

Berdasarkan penjelasan yang telah diuraikan di atas, maka penelitian ini bertujuan untuk mencari faktor-faktor yang mempengaruhi kemampuan inovasi UKM dan peran Pemerintah pada inovasi UKM.

\section{Metode}

\section{a. Model Konseptual}

Model konseptual pada penelitian ini diawali dengan adanya peran pemerintah dalam inovasi UKM. Beberapa penelitian yang telah melakukan pengukuran peran stakeholder antara lain Zeng et al. (2010), dan Lai (2011). Dari penelitian-penelitian tersebut diketahui bahwa peran stakeholder sangat penting bagi lembaga perantara dalam mendukung efektifitas transfer teknologi dan kinerja inovasi perusahaan, baik 
melalui inovasi produk maupun inovasi proses. Namun pengukuran pada penelitianpenelitian terdahulu masih bersifat parsial, sehingga penting untuk mengadopsi dan melakukan penelitian yang secara bersama-sama melibatkan peran peran Pemerintah terhadap faktor-faktor inovasi UKM.

Menurut Wati dan Satrio (2015) Variabel-variabel yang akan di gunakan pada penelitian perlu didefenisikan agar tidak terjadi perbedaan cara pandang. Berikut ini adalah tabel defenisi variabel penelitian

Tabel 2. Variabel penelitian

\begin{tabular}{|c|c|}
\hline Variabel & Defenisi Operasional \\
\hline Peran Pemerintah & $\begin{array}{l}\text { Menggambarkan kemampuan Pemerintah melakukan } \\
\text { pembinaan dan pendampingan UKM untuk } \\
\text { mengembangkan inovasi UKM, yang diukur dari penilaian } \\
\text { peran pemerintah dalam membantu UKM untuk } \\
\text { mengembangkan kemampuan inovasi UKM, Herliana } \\
(2015)\end{array}$ \\
\hline Pembelajaran & $\begin{array}{l}\text { Menggambarkan komitmen untuk belajar yang diukur dari } \\
\text { penilaian sampai dimana derajat keseriusan UKM } \\
\text { berkomitmen untuk belajar, Taufiqurrahman, (2012) }\end{array}$ \\
\hline $\begin{array}{l}\text { Teknologi } \\
\text { Informasi }\end{array}$ & $\begin{array}{l}\text { Menggambarkan penggunaan teknologi terbaru yang diukur } \\
\text { dari penilaian sampai dimana derajat penggunaan teknologi } \\
\text { canggih oleh UKM (Moeuf et al., 2017) }\end{array}$ \\
\hline Inovasi UKM & $\begin{array}{l}\text { Menggambarkan keuntungan relatif inovasi yang diukur dari } \\
\text { penilaian sampai dimana sumber keuntungan kompetitif } \\
\text { untuk sebuah produk memiliki titik diferensiasi. Nugroho et } \\
\text { al. (2017) }\end{array}$ \\
\hline
\end{tabular}

Model dikembangkan dari penelitian-penelitian terdahulu dan studi literatur yang mengulas peran Pemerintah. Terdapat 6 variabel yang digunakan dalam penelitian ini. Selanjutnya model konseptual dan hipotesis penelitian ditetapkan dari variabel-variabel yang diduga mempunyai hubungan pada peran Pemerintah dalam meningkatkan inovasi UKM. Model tersebut memperlihatkan: hubungan Pemerintah dengan faktor faktor yang mengaruhi inovasi UKM, hubungan Pemerintah dengan inovasi UKM dan hubungan faktor-faktor yang mempengaruhi inovasi UKM terhadap inovasi UKM.

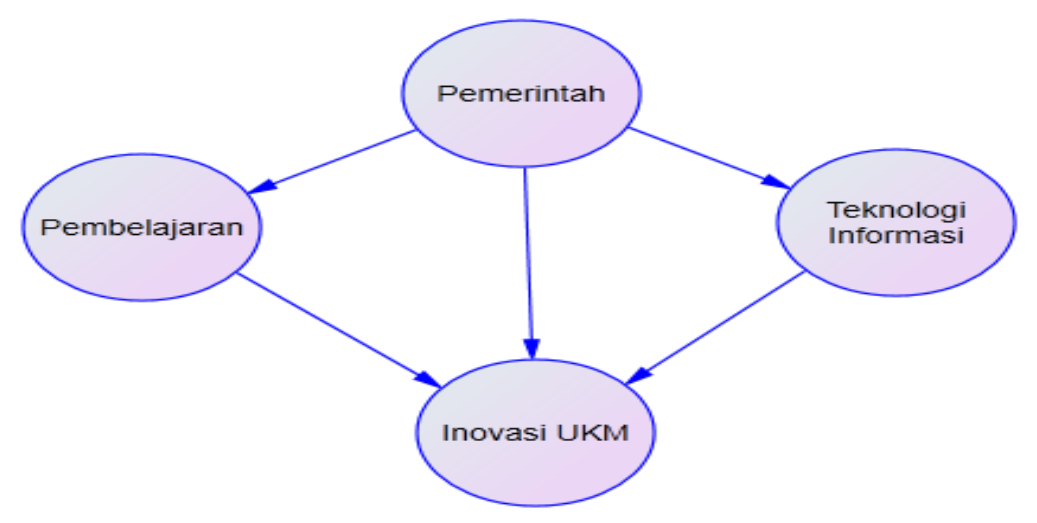

Gambar 1. Model Konseptual peran Pemerintah dan faktor-faktor inovasi pada UKM 
Hipotesis penelitian yang dibangun dari hubungan antar variabel adalah : Hipotesis 1: Peran Pemerintah berhubungan signifikan terhadap pembelajaran Hipotesis 2:

Peran Pemerintah berhubungan signifikan terhadap teknologi informasi Hipotesis 3 :

Peran Pemerintah berhubungan signifikan terhadap inovasi UKM Hipotesis 4:

Pembelajaran berhubungan signifikan terhadap inovasi UKM

Hipotesis 5: Teknologi informasi berhubungan signifikan terhadap inovasi UKM

\section{b. Pengumpulan Data dan analisi data}

Pengumpulan data dilakukan dengan kuesioner dengan penilaian responden pada indikator penelitian menggunakan skala likert dengan skor 1 (sangat tidak setuju), 2 (tidak setuju), 3 (kurang setuju), 4 (setuju), dan 5 (sangat setuju) untuk mengukur sikap, pendapat, dan persepsi responden (Ghozali dan Fuad, 2008). Secara garis besar, kuesioner didesain untuk mendapatkan data-data yang mengkonstrak variabel penelitian. Lokasi penelitian terdapat di wilayah Kota Gorontalo. Metode yang digunakan dalam pengolahan data untuk mengkonfirmasi hubungan dalam model adalah SEM dengan AMOS 20.

Pada penelitian ini, pengolahan data dilakukan dengan metode SEM. Pengujian model struktural menggunakan estimasi model maximum likelihood. Tahapan model struktural ini berfungsi untuk memastikan apakah model telah sesuai dengan data atau model telah fit, dan memastikan ada tidaknya pengaruh antar variabel yang diteliti (untuk keperluan pengujian hipotesis), serta kekuatan hubungan dengan melihat nilai loading factor.

\section{Hasil dan Pembahasan}

Hasil pengolahan data dengan menggunakan SEM AMOS pada penelitian ini menghasilkan nilai kriteria CMIN/DF, GFI, RSMEA, NFI dan TLI telah fit dan memenuhi standar sesuai dengan batas yang direkomendasikan. Sedangkan nilai CFI dan AGFI menunjukkan model tidak fit seperti yang ada pada tabel 4. Mengacu pada Solimun (2002) bahwa hasil model dikatakan telah fit, jika ada salah satu atau dua kriteria fit model telah terpenuhi. Dari berbagai indeks kesesuaian tersebut dapat disimpulkan bahwa model struktural yang diajukan fit atau mempunyai kesesuaian yang baik.

Tabel 4. Hasil Pengukuran Tingkat Kesesuaian (goodness-of-fit model)

\begin{tabular}{llll}
\hline \multicolumn{1}{c}{ Goodness of Fit Statistics } & Cut of Value & Hasil Model & Kriteria \\
\hline CMIN/DF & $<2,0$ & 1,652 & Baik \\
GFI & $\geq 0,90$ & 0,603 & Baik \\
RMSEA & $\leq 0,08$ & 0,048 & Baik \\
CFI & $\geq 0,90$ & 0.870 & Kurang \\
AGFI & $\geq 0,90$ & 0,862 & Kurang \\
\hline
\end{tabular}




\begin{tabular}{llll}
\hline Goodness of Fit Statistics & Cut of Value & Hasil Model & Kriteria \\
\hline NFI & $\geq 0,90$ & 0,897 & Baik \\
TLI & $\geq 0,90$ & 0,889 & Baik \\
\hline
\end{tabular}

Sumber : Output AMOS

Pada tahap pengujian hipotesis akan di analisis pengaruh antara variabel independen terhadap variabel dependen. Pengujian hipotesis yang dilakukan dengan melihat path coefficients yang menunjukkan koefisien parameter dan nilai signifikansi t statistik. Signifikansi parameter yang diestimasi dapat memberikan informasi mengenai hubungan antar variabel-variabel penelitian. Batas untuk menolak dan menerima hipotesis yang diajukan yaitu menggunakan probabilitas 0,05 (Santoso, 2012).

Adapun hasil uji hipotesis adalah sebagai berikut:

1. Peran Pemerintah berpengaruh terhadap pembelajaran, karena nilai $t$ hitung $>\mathrm{t}$ tabel $(26,991>1,96)$ atau $P$ values $<0,05(0,000<0,05)$, sehingga Ho ditolak. Nilai koefisien positif sebesar 0,792 artinya pengaruhnya positif, yaitu jika Peran Pemerintah meningkat maka pembelajaran juga meningkat, dan sebaliknya.

2. Peran Pemerintah berpengaruh terhadap teknologi informasi. Hal ini karena nilai $t$ hitung $>t$ tabel $(25,855>1,96)$ atau $P$ values $<0,05(0,000<0,05)$, sehingga Ho ditolak. Nilai koefisien positif sebesar 0,808 artinya pengaruhnya positif, yaitu jika Peran Pemerintah meningkat maka teknologi informasi juga meningkat, dan sebaliknya.

3. Peran Pemerintah berpengaruh terhadap inovasi UKM. Hal ini karena nilai thitung $>t$ tabel $(2,579>1,96)$ atau $P$ values $<0,05(0,010<0,05)$, sehingga Ho ditolak. Nilai koefisien positif sebesar 0,293 artinya pengaruhnya positif, yaitu jika Peran Pemerintah meningkat maka inovasi UKM juga meningkat, dan sebaliknya.

4. Pembelajaran tidak berpengaruh terhadap inovasi UKM. Hal ini karena nilai $t$ hitung $<\mathrm{t}$ tabel $(0,639<1,96)$ atau $P$ values $>0,05(0,523>0,05)$, sehingga Ho diterima.

5. Teknologi informasi berpengaruh terhadap inovasi UKM. Hal ini karena nilai $t$ hitung > t tabel $(19,579>1,96)$ atau $\mathrm{P}$ values $<0,05(0,008<0,05)$, sehingga Ho ditolak. Nilai koefisien positif sebesar 0,293 artinya pengaruhnya positif, yaitu jika Peran Pemerintah meningkat maka inovasi UKM juga meningkat, dan sebaliknya.

\section{Kesimpulan}

Faktor-faktor yang mempengaruhi kemampuan inovasi UKM pada penelitian ini adalah Pemerintah dan teknologi informasi sedangkan pembelajaran tidak berpengaruh secara signifikan terhadap inovasi UKM. Selain memepengaruhi inovasi 
UKM, Pemerintah juga mempengaruhi semua faktor-faktor yang berperan dalam meningkatkan kemampuan inovasi UKM.

Pengembangan kemampuan inovasi UKM dalam menghadapi persaingan global dapat dilakukan dengan: memaksimalkan peran Pemerintah melalui peningkatkan pembelajaran pada UKM, berupaya untuk menggunakan teknologi informasi yang lebih maju, dan menciptakan produk yang lebih inovatif dan berkualitas.

Saran untuk penelitian mendatang adalah perlunya kolabarasi antara pemerintah dan perguruan tinggi untuk meningkatkan inovasi UKM

\section{Daftar Pustaka}

Asmoro, Udisubakti, Supriyanto, 2012, Perancangan Incubator model triple helix untuk efektivitas proses knowledge transfer sebagai strategi pengembangan IKM Proceeding Pekan IImiah Dosen FEB -UKSW, 13-26.

Baker \& Sinkula. 1999. Learning oriantation, market orientation and innovation: integrating and extanding models of organization perfoemance. Journal of Marketing Focused Management, Vol. 4, p. 295-308.

Baroroh, Partiwi, Anityasari, M. 2010. Siklus hidup klaster inisiasi pemerintah: sebuah studi perbandingan. 2010, Thesis, Institut Teknologi Sepuluh November (ITS).

Bello, Aminu, Adamu, Ibrahim (2015), Impact of Small and Medium Scale Enterprises on Economic Growth : Evidence from Nigeria, Journal of Economics and Business, 4, $236-244$.

Chughtai, M. W., (2014), Impact of Small and Medium Enterprises on Economic Growth: Evidence from Pakistan, Journal of Business Management, 2(July), pp. 19-24.

Etzkowitz, 2008, The triple helix: university, industry, government innovation in action, Bab 6, Routledge.

Ganzarain, Errasti, 2016, Three Stage Maturity Model in SME 's towards Industry 4.0, Journal of Industrial Engineering and management, 9, 1119-1128.

Herliana, sri., 2015. Regional Innovation Cluster for Small and Medium Enterprises ( SME ): A Triple Helix Concept, 169, 151-160.

Leydesdorff, L. and H. Etzkowitz. 1996. Emergence of a Triple Helix of UniversityIndustry-Government Relations, Science and Public Policy 23 (5): 279-286.

Martinez, Maria, Gonzalo, 2018, The Relationship Between Market orientation, Entrepreneurial orientation, and Learning Orientation on Innovation and its effect on performanca in mexican SMEs, International Business Management, 12(2), 132-144

Moeuf, Alexandre Pellerin, Robert Lamouri, Samir Tamayo-giraldo, Simon, 2017, The 
industrial management of SMEs in the era of Industry 4.0, International Journal of Production Research, 1-17.

Nugroho, 2017, The Effect Of Competing Ability And The Role Of Triple Helix Model On Performance Of Micro-Small-Middle Enterprises In Sidoarjo Regency, International Journal of advaced research, 5, 1465-1472.

Ogbuanu, B. K., Kabuoh, M. N. and Okwu, A. T., (2018) 'Relevance Of Small And Medium Enterprises In The Growth Of The Nigerian Economy : A Study Of Manufacturing SMEs', International Journal of Advanced Research in Statistics, Management and Finance, 2(1), pp. 180-191.

Su, Y.S. \& Hung, L.C. 2009. Spontaneous vs. policy-driven: The origin and evolution of the biotechnology cluster. Technological Forecasting \& Social Change Vol. 76 p. 608-619.

Tambunan, (2011),"Development of small and medium enterprises in a developing country", Journal of Enterprising Communities: People and Places in the Global Economy, Vol. 5 Iss 1 pp. 68 - 82.

Taufiqurrahman, (2012), PEMBINAAN DAN Pengembangan Kemampuan Inovasi UMKM Dan Peran Intermediary Pada Ukm Kerajinan, Tesis, Institut Teknologi Sepuluh Nopember.

Ülengin, Kabak., Önsel, Ülengin, B. \& Aktas, E. 2010. A problem-structuring model for analyzing transportation-environment relationships. European Journal of Operational Research. Vol. 200, P. 844-859. 